\title{
A trajetória de João Cruz Costa e a formação da filosofia uspiana: algumas considerações sobre o campo intelectual brasileiro nas décadas de 1940 e 1950
}

\section{Francini Venâncio de Oliveira*}

Resumo: Pretende-se reconstruir o itinerário intelectual do filósofo e historiador das ideias João Cruz Costa, tendo em vista discutir o projeto político que perpassa o conjunto de sua obra e, ainda, a importância que a Universidade de Sáo Paulo - seu locus por excelência de trabalho - teve para sua trajetória. O objetivo, nesse sentido, é ampliar o foco de análise e matizar o papel que instituiçôes como a USP, assim como o IsEB, tiveram para uma geração de intelectuais brasileiros que, em meados do século XX, envolveu-se com velhos e conhecidos temas do pensamento social brasileiro e reacendeu o debate em torno dos problemas de formação de nosso campo intelectual.

Palavras-chave: João Cruz Costa; campo intelectual brasileiro; filosofia; USP; IsEв.

\section{The trajectory of João Cruz Costa and the formation of philosophy at Universidade de} Sáo Paulo: some notes on the Brazilian intellectual field in the 1940's and 1950's

Abstract: The present paper reviews the intellectual trajectory of João Cruz Costa, professor of philosophy at the Universidade de Säo Paulo. The political relevance of his works is discussed in order to assess the role of that university and of institutions such as ISEB in the formation of a Brazilian intelligentsia in the 1940s and 1950s. This analysis assumes (a priori) that there was a close relation between the intellectual trajectories of the main social agents and the institutional transformations which took place in Brazil at that time.

Keywords: João Cruz Costa; Brazilian intellectual field; philosophy; USP; ISEB.

\footnotetext{
* Bacharel em Filosofia e mestre em Sociologia pela Universidade de São Paulo. Atualmente é doutoranda pelo Programa de Pós-Graduação em Sociologia da FFLCH/USP e bolsista do CNPQ.
} 
À luz do pensamento social ou, se preferir, do ponto de vista de uma história intelectual brasileira, poder-se-ia afirmar que a década de 1950 ficou conhecida, de maneira semelhante ao ocorrido na década de 1930, pela iniciativa de nossos intelectuais em interpretar o Brasil, embora com matiz agora diverso, a começar pelo ensejo de alguns desses novos personagens em intervir na organização política e econômica do país - fato que, vale lembrar, provocaria polêmicas, mas também iluminaria as lutas simbólicas travadas por essa intelectualidade em meados do século XX.

Para dizer de outro modo, a arena política e intelectual dos anos 1950 voltou-se para a assim chamada "realidade brasileira" e, portanto, fez com que seus atores discutissem exaustivamente questóes que de certo modo permanecem vivas no campo político-cultural, bem como cunhassem termos hoje já popularizados, caso, por exemplo, do conceito de autonomia nacional, entre outros.

No Rio de Janeiro, entre os intelectuais do IseB, o estudo de nossa "realidade" implicava um plano de desenvolvimento para o Brasil e, portanto, havia implícita a ideia de transformaçãa ${ }^{1}$. Em São Paulo, embora em um registro analítico distinto daquele que vicejara no Instituto, sobretudo entre os sociólogos da USP reunidos em torno da figura de Florestan Fernandes, eram nítidas as preocupaçóes com a questão do negro e com a estrutura de nossas relaçóes sociais e inter-raciais².

O retrato apresentado é sem dúvida muito breve e parcial para, a partir dele, tirarmos qualquer conclusão acerca do campo intelectual brasileiro no período estudado. Não obstante, ele nos permite imaginar (minimamente, cabe reconhecer) a ambiência social e cultural dos intelectuais à época. Em outras palavras, tal retrato - ainda que fragmentário - nos possibilita captar possíveis e prováveis dinâmicas da vida intelectual brasileira ao longo da década de I950, mas não só: ver-se-á que o quadro esboçado, ainda que breve, também é de grande valia para compreender a trajetória e a obra de um personagem ligado institucionalmente à tradiçáo filosófica uspiana e, portanto, a um estilo de trabalho intelectual muito singular que começava a ganhar corpo na Universidade de Sáo Paulo.

Tendo em mente tal cenário, quem foi, afinal, João Cruz Costa? E quais foram, enfim, as condiçôes sociais e institucionais de sua produçáo intelectual? Partindo de tais questóes, este texto visa a presentar parte de sua trajetória e obra, bem como problematizar o lugar por ele ocupado em um campo, em meados do século XX, que se encontrava em formaçáo.

De família abastada ${ }^{3}$ e dono de uma cultura densa e múltipla, o filósofo e historiador das ideias João Cruz Costa desejava, a princípio, seguir carreira médica e, como tal, foi fazer na

I Para maiores detalhes, consultar Ortiz (1985). Também são esclarecedores, nesse sentido, o trabalho pioneiro de Caio Navarro de Toledo (I977), e o de Lúcia Lippi Oliveira (1995).

2 A esse respeito, veja-se, entre outros, o valioso artigo de Maria Arminda do Nascimento Arruda (1997).

3 Cruz Costa era filho de pai português e descendente de italianos por parte de mãe. Com boa situação financeira, passou a mocidade na França, chegando a ter acesso a instituiçóes famosas como a Sorbonne e o College de France. 
França um curso preparatório para a Faculdade de Medicina de Paris. Estando em um rico centro humanístico, passou também a estudar filosofia, desviando aos poucos seu foco de interesse, como ele mesmo reconheceu:

[...] comecei estudando medicina, revelando assim um interesse prático pelo homem, se não por ele, por sua saúde. Eu fizera aqui uns vagos estudos de filosofia com meu saudoso amigo, prof. Henrique Geenen, para satisfazer as exigências dos preparatórios. Para ingressar na Faculdade de Medicina éramos obrigados a prestar exame de psicologia e lógica, que o meu amigo e professor da Faculdade de Medicina, o professor Guilherme Bastos Milward, chamava de psicologia ilógica. Fui depois para a França em I923 e entrei no curso preparatório da Faculdade de Medicina de Paris. Um dia, num grupo de brasileiros, encontrei o prof. George Dumas, que era grande amigo do Brasil, que me perguntou qual a especializaçáo que eu iria fazer na medicina. A minha resposta foi: a psiquiatria. O velho Dumas, que era médico e agrégé de Filosofia, aconselhou-me então que fizesse estudos de filosofia e convidou-me para assistir às suas divertidas aulas aos domingos, no Asyle de St'Anne. Inscrevi-me como ouvinte nos cursos à Sorbonne, assistindo às aulas dos profs. Brunschvicg, Salande, assim como as de Pierre Janet no Colégio de França (Costa, 1974. pp. 87-8).

Ao voltar ao Brasil, tornou-se, então, o aluno "número um" inscrito na Faculdade de Filosofia da Universidade de Sáo Paulo, onde, por fim, construiria sua carreira, doutorando-se em 1942 e tornando-se, primeiramente, assistente, depois substituto da cátedra de seu mestre francês Jean Maugüé, entre 1945 e 1965 . Mas talvez só tenha se tornado um autor conhecido no país após a publicação, em I956, do livro Contribuiçấo à História das Ideias no Brasil - obra voltada para o exame das origens da vida intelectual brasileira e que corresponde originalmente à tese apresentada pelo autor ao concurso da cadeira de Filosofia da Faculdade de Filosofia, Ciências e Letras da Universidade de São Paulo, hoje denominada Faculdade de Filosofia, Letras e Ciências Humanas.

Interessado na história da imigração das ideias estrangeiras e, portanto, em nossos problemas de formação, João Cruz Costa almejou formular e "viabilizar" uma filosofia que estivesse fundamentada em um projeto nacional autônomo. Defendeu, assim, a necessidade de uma visão de trabalho filosófico voltado para a sociedade brasileira, pautando sua reflexão pelos caminhos de nossa condiçáa histórica e destacando, sobretudo, a importância do advento do positivismo entre nós por se tratar, segundo o autor, de um fenômeno relacionado ao "momento de maior transformaçáo da história brasileira” (CosTA, 1956, p. 138). Talvez por isso tenha publicado tantos artigos sobre o assunto, além de dois livros inteiramente dedicados ao tema, deixando evidente, a meu ver, um dos traços que mais chamariam a atenção no conjunto de sua obra, isto é, seu enorme interesse pela evolução das ideias filosóficas no Brasil ou, segundo ele próprio denominaria, pela evoluçäo histórica nacional. 
Tal fato me parece curioso náo só por abarcar um esforço de análise e de interpretaçăo conforme o debate intelectual que prevaleceu nas décadas de 1940 e 1950, mas principalmente por iluminar o que considero uma de suas formas de interpretar o Brasil, interpretação essa que se aproximava em muito de um debate produzido e veiculado pelos intelectuais do IsEB, sem dúvida, mas que também recolhia traços dessa filosofia positivista que o autor tanto desejara analisar, haja vista sua recorrência na utilização de termos como "evoluçáo", "universal", "progresso", ao longo de suas reflexóes.

Em Augusto Comte e as Origens do Positivismo (1959), por exemplo, Cruz Costa apresentou sumariamente o pensamento de Comte, ensejando discorrer sobre seu significado. $\mathrm{O}$ autor justificou a importância do tema alegando ser o positivismo uma corrente cujas influência e história ainda náo haviam sido terminadas, principalmente no Brasil. Utilizando as palavras de Otto Maria Carpeaux, escreveu no Prefácio à segunda edição que "o positivismo brasileiro [...] 'é um símbolo de realidades mais profundas' que talvez, no seu devir, podem esclarecer algumas das possíveis constantes da nossa maneira de ser" e, apoiando-se nas aulas dos mestres franceses, definiu Augusto Comte como "o orquestrador de duas teses contraditórias: a da análise positiva e a da síntese romântica" - pensamento este que, enfim, representaria "um dos grandes momentos da 'filosofia científica", cujo impacto nas Américas deveria ser levado em conta.

Segundo João Cruz Costa, as ideias comtianas também seriam relevantes por terem trazido à reflexão filosófica uma nova contribuição, qual seja, a Sociologia - ciência vista com bons olhos por tornar, segundo ele, "mais rica e mais fecunda" a investigaçáo dos filósofos, ao contrário de empobrecê-la ${ }^{4}$. Entretanto, o que mais importava salientar na obra de Comte era a ideia de ordem, que táo fortemente marcava sua produçáo e que reapareceria de modo mais claro e vivo nas consequências políticas de sua filosofia, sendo justamente a Sociologia a fornecedora dos princípios dessa suposta "ordem filosófica".

Nesse esforço de síntese do pensamento de Comte, Cruz Costa ainda chamou a atençáo do leitor para o fato de nele se perceberem "duas cousas diferentes", quais sejam: uma seria a doutrina pessoal do filósofo; outra, de natureza distinta, o "pensamento geral de que o comtismo é apenas uma forma ou expressão" (CosTA, I959, p. I) e que, portanto, a ultrapassa.

Daí, pois, o sentido da breve reconstrução feita por Cruz Costa da história da filosofia e da ciência para afirmar que tal modo de conceber a filosofia "resulta [...] da própria evoluçáo das ciências", sendo a aversão positivista a toda a metafísica e a toda e qualquer especulação que ultrapasse os domínios da experiência e dos objetos da observação sensível, fruto das modificaçôes científicas e filosóficas dos séculos XVI e XVII, responsáveis pela ampliação do campo da observação humana no período:

Um grande número de fatos foi explicado, fatos estes que o passado náo conhecera $\mathrm{e}$ (sic) que nem talvez suspeitara. Os descobrimentos marítimos dos portugueses e dos

4 Todas as citaçôes presentes neste parágrafo foram extraídas do Prefácio à segunda edição da obra de Cruz Costa (I959, pp. xi-xiii). 
espanhóis haviam revelado ao velho mundo novos mundos; as novas contribuiçóes que as ciências naturais trouxeram para o conhecimento do homem determinariam uma ruptura decisiva com os velhos moldes culturais. Uma cultura nova, de base experimental e de tendência crítica, repontara com o Renascimento. Esta orientação nova, crítica e já quase experimental do século XVI, sempre atenta à continuada experiência, desenvolver-se-ia principalmente no século XVII (CosTA, I959, pp. 2 e 3).

Tal contexto, de acordo com o autor, ajudaria a explicar o fato de a doutrina comtiana se servir do "método elaborado pelos físicos aos fatos descobertos pelos políticos" (CosTA, I959, pp. 2 e 3). Mas o autor ainda lembra que "a doutrina de Augusto Comte deriva também dos acontecimentos sociais, econômicos e políticos que sucederam à Revolução de I789”, de tal modo que Comte náo teria escapado, como outros pensadores contemporâneos, "do desejo de encontrar base estável para a vida social e política” (CosTA, I959, p. 5). Daí o predomínio, à época, de reformadores sociais de caráter missionário em meio à intelectualidade europeia.

Em termos analíticos, tais observaçóes não soam, obviamente, como novidade: configuram, antes de tudo, uma grande síntese das principais teses dos historiadores franceses acerca do assunto, realizada por nosso autor. Porém, se faço questão de destacar aqui essas passagens é porque penso que elas iluminam náo somente parte da produçáo intelectual cruzcostiana, mas também - e sobretudo - ajudam a delimitar a posição do autor em relação aos seus pares, isto é, os filósofos da Universidade de São Paulo.

Para ser mais clara, parece-me que tais observaçóes corroboram o desejo de João Cruz Costa de se distanciar de uma atividade intelectual - a filosofia ou, ao menos, certo tipo de filosofia caracterizada sobretudo pela recusa da História, náo obstante estar ligada a ela institucionalmente. Como será possível notar logo mais, tal fato marcaria sua carreira e traria consequências para sua trajetória na referida universidade - ambiente este que, cabe lembrar, em meados da década de I950, começava a dar seus primeiros passos em direçáo a um processo de institucionalizaçáo que marcaria o campo intelectual uspiano, já que, guiada por critérios de cientificidade que culminariam na exigência de "padróes acadêmicos" impostos à elaboração de ideias, como bem mostra a socióloga Maria Arminda do Nascimento Arruda, a universidade criaria "condições institucionais à produçáo do conhecimento", congregando um número significativo de intelectuais e transformando, dessa forma, os "critérios de produção do saber" - critérios estes que exigiriam das novas geraçóes um projeto filosófico "autônomo", "universalista" e "científico", em oposição ao diletantismo e ao amadorismo da intelectualidade modernista (ARRUDA, 200I, pp. 20I-204).

$\mathrm{Na}$ tentativa de elaborar uma "filosofia engajada", amarrada à açáo e sustentada pelo ensaísmo diletante da geração de 1930, João Cruz Costa parece ter se aproximado muito mais dos intelectuais Isebianos do que de seus colegas uspianos, ou melhor, a aproximaçáo defendida por João Cruz Costa do exercício filosófico da assim denominada cultura nacional parece ter deslocado o autor a uma espécie de "ostracismo intelectual" no que se refere aos seus pares, ao menos do ponto de vista do (não) reconhecimento de sua produção e, portanto, de seu legado 
- não obstante as diversas e relevantes funçóes político-administrativas ocupadas e acumuladas no interior da Faculdade durante os vinte anos em que ali permaneceu.

As observaçôes de Paulo Arantes são, nesse sentido, muito esclarecedoras do ponto de vista das regras do jogo que se jogava nesse campo em particular: a filosofia paulista teria aos poucos ganhado ares de disciplina intelectual destinada a remediar os males da dependência e, seguindo à risca os princípios da escola francesa (que repudiava toda e qualquer forma de "literatice"), o campo filosófico uspiano foi, lentamente, desenvolvendo o que se convencionou chamar de filosofia do conceito, exigindo de seus pares o distanciamento político e o "vácuo histórico" necessários. Pregava-se, quanto à leitura dos textos:

Como é sabido, um dos lugares comuns de nossa tradiçấo cultural concerne o caráter progressista do interesse pelo assunto nacional, via de regra mascarado pela cortina de fumaça da novidade metropolitana, consumida sem critério pelo bovarismo das elites divorciadas do país real. [...] Contrariando a referida tradiçăo, ocorre que a implantaçáo de um curso superior de filosofia nos moldes franceses conhecidos estabeleceu uma divisão de águas inversa: a universalidade dos grandes temas [...] seria apanágio da filosofia universitária, mas rigorosa e politicamente avançada, [...] enquanto o localismo, tão acanhado quanto a inequívoca nulidade dos escritos filosóficos nacionais, ficava por conta dos espíritos mais retrógrados ou simplesmente mais despreparados (Arantes, 1994, p. 90).

Bento Prado Jr. (1985), em envolvimento, certa feita, com a situaçáo e os problemas da Filosofia no Brasil, enfatizaria, assim, que um dos erros maiores de Cruz Costa estaria em sua tentativa de buscar construir a filosofia brasileira (e, portanto, o que ela deveria ser) com base em um "nacionalismo duvidoso" - concluindo que, "nessa busca do tempo perdido, há algo de patético, algo como uma Nação à procura do seu próprio “espírito"” (Prado JR., 1985, p. 190).

Os comentários de Bento, como esclarece Paulo Arantes, estão inseridos em uma "questão de princípio" do exercício filosófico uspiano, pois, segundo tal campo intelectual, "tomar a filosofia como a 'expressão' de algo que a precede é não só ferir a 'autonomia da história da filosofia' e desnaturar o 'próprio discurso filosófico' como também condenar-se a 'não distingui-la jamais da mera ideologia'” (ARANTES, I994, p. 95).

Como bem notou Pierre Bourdieu (2002, p. 28I), é compreensível que métodos e técnicas sejam componentes do ensino, mas, nesse caso, o método estrutural - escondendo-se por meio dessa pretensa "universalidade" do discurso filosófico - corrobora a "dissimetria radical que a filosofia institui [...] na sua relação com as ciências do homem", de modo a excluir demais discursos que "não caberiam" à instituição filosófica, tratando-se, em suma, de um "fetichismo do texto autônomo", de um "culto da técnica tratada como fim em si" (Bourdieu, 2002, p. 265).

Em suma, apesar de Cruz Costa ter sido professor catedrático de 1954 a 1965, quando enfim se aposentou - o que, obviamente, demandava a conquista de certo prestígio e poder entre os 
pares e evidenciava, sem dúvida, a capacidade desse intelectual em estabelecer alianças políticas e, portanto, acumular capital no interior do campo filosófico uspiano ${ }^{5}-$, estou aqui levantando a hipótese de que, ao menos no que se refere ao seu específico ambiente de trabalho, a Universidade de Sáo Paulo, ele parece ter, do ponto de vista da produçáo intelectual e, portanto, do conjunto de sua obra, uma atuação mais apagada, não obstante seu considerável poder político.

Por conta desse prestígio político, isto é, por ter sido capaz de estabelecer uma rede de relaçóes com personagens de grande capital dentro e fora da universidade, criando laços de amizade e de convivência com diretores e ex-diretores da faculdade e com políticos de destaque na cena paulista no período estudado ${ }^{6}$ é que talvez se possa explicar sua (paradoxal) centralidade para a formação do campo filosófico uspiano, tendo sido um dos responsáveis, nos anos de 1950 e 1960, pela vinda de importantes filósofos ao Brasil, tais como Martial Guéroult, Michel Debrun, Gilles Gaston Granger, entre outros; e por enviar para a França igualmente estudantes que depois se tornariam náo só estrelas da casa, como teriam grande destaque no cenário nacional, como, por exemplo, José Arthur Giannotti e Marilena Chauí.

Todavia, considerando uma vez mais sua produçáo intelectual, Joáo Cruz Costa parecia estar consciente de suas vicissitudes, chegando mesmo a revelar no prefácio à Contribuição à História das Ideias no Brasil que tal obra, em princípio sua tese de doutoramento, "é resultado das notas que colhera e se não é trabalho original e profundo, talvez seja de alguma utilidade para aqueles que tentam compreender o pensamento nacional" (CosTA, 1956).

A correspondência mantida ao longo dos anos de 1944 e 1945 com o historiador e amigo íntimo Eurípedes Simóes de Paula (homem de grande poder institucional, diga-se de passagem, já que chegou a ser diretor da Faculdade) é o que há de mais revelador nesse sentido; não só porque os receios e as incertezas desse intelectual se anunciam diante de um quadro político em processo de transformaçáo, mas, sobretudo, porque o tipo de capital por ele acumulado, bem como a posiçáo ocupada no interior da Faculdade de Filosofia, é claramente denunciado, de modo que sua rede de sociabilidade é, também, aos poucos "descoberta".

A título de exemplo, em uma das primeiras cartas enviadas ao amigo, Cruz Costa não esconde o entusiasmo, mas também certa apreensão, diante das mudanças institucionais que enfim atingiriam a Universidade de São Paulo:

Simões amigo:

[...] tu não sabes que daqui a pouco serás catedrático. Talvez, seria melhor dizer. Talvez, pois a reforma do Ensino Superior ainda náo foi publicada. Vai se criar a carreira. Só

\footnotetext{
5 Para maiores detalhes acerca do funcionamento, bem como dos tipos de capital simbólico de cujos agentes se servem nos espaços científicos e acadêmicos, consultar os trabalhos de Pierre Bourdieu, sobretudo Os usos sociais da ciência (2004); Homo Academicus (1984); e As regras da arte (1996).

6 Basta lembrar, aliás, que sua principal obra é dedicada à memória de Armando Salles Oliveira, que, como se sabe, foi governador do Estado de São Paulo e um dos responsáveis pelo projeto, bem como pela consolidação da USP na década de 1930 .
} 
será professor aquele que fizer carreira e nós já fizemos algumas das etapas mais importantes. Fala-se até em efetivação. Em todo caso, estão fora de possibilidade os tais paraquedistas. Só quem fizer carreira. É cousa muito boa. Logo que eu tenha noticias das minúcias da nova reforma, hei de te escrever contando tudo. E estou aqui firme. Se eu for catedrático, tu também hás de ir. Aliás, todos estâo firmes na vigilância 7 .

Considerando tais mudanças, é interessante notar, ainda, a nítida insegurança e o sincero desabafo do remetente em uma das cartas seguintes:

[...] A tal Reforma do Estado ainda não saiu e nada há ainda quanto aquela história dos interinos que contei a $\mathrm{V}$. na minha última carta. Mas, esteja tranqüilo, pois estamos vigilantes no que se relaciona com a sua cadeira.

$O$ diretor convidou-me para fazer concurso em setembro de 45. Naturalmente aceitei, pois não podia dar parte de fraco. Não quero bancar o corajoso, mas creio que hei de ter grandes dificuldades e que talvez chegue mesmo a dizer adeus aos meus amigos. V. sabe, filosofia cá na terra ainda é cousa de padre. Enfim, irei até ver em que dáo as cousas. Se não der certo, far-se-á outra cousa. O Brasil é grande. Depois, até setembro de 45, muita água ainda há de correr nos diversos rios deste e de outros continentes. [...] Eu ainda não tenho nem sequer um assunto. Prefiro cousa cá da terra e talvez estude o Positivismo, assunto que me interessa muito pelas ressonâncias que apresenta. É uma "gaita" perder um lugar, mas que fazer? ${ }^{8}$

Em linhas gerais, se por um lado as cartas evidenciam o poder político e administrativo reunidos por Joấo Cruz Costa no interior da Faculdade de Filosofia, por outro corroboram e talvez ajudem a explicar sua fragilidade intelectual no tocante à produçẫo e recepçấo de sua obra nesse ambiente em particular, como já mencionado.

III

Por se tratar de uma pesquisa em andamento, as questóes aqui levantadas estáo longe de terem sido esgotadas, e muitos pontos encontram-se, obviamente, eclipsados, exigindo maiores cuidados e amadurecimento. Mas, à guisa de conclusáo do presente texto, cabe esclarecer que, no momento, o que estou tentando compreender é o lugar ocupado por João Cruz Costa na Universidade de São Paulo, a partir das mudanças institucionais que nela ocorreram em meados do XX, mas também a partir das redes de sociabilidade estabelecidas pelo autor nesse ambiente, que, cabe lembrar, não só ajudou a formar e a consolidar o campo da ciência no Brasil, bem como definiu e solidificou um estilo de trabalho intelectual muito significativo para o país, embora

7 Carta de JCC a ESP, datada de I4/08/1944. Grifos colocados (CAPH, arquivo/correspondência de ESP, nº. 175I, cx. 23). 8 Carta de JCC a ESP, datada de 28/08/1944. Grifos colocados (CAPH, arquivo/correspondência de ESP, nº. 1757, cx. 23). 
não exclusivo -uma vez que, se retomada aquela cena inicial acerca da ambiência social, política e cultural da intelectualidade brasileira no período estudado, talvez me seja permitido indagar: até que ponto a suposta posiçấo de Joáo Cruz Costa no interior do campo uspiano corresponde à posição por ele ocupada em âmbito nacional e até mesmo internacional? As mudanças institucionais de seu específico locus de trabalho teriam, de fato, moldado e estabelecido os parâmetros de sua trajetória e de sua obra?

Considerando a tradição Isebiana e/ou à luz de uma história das ideias latino-americana, talvez se possa argumentar que seu lugar, em princípio, é outro - tratando-se de um personagem, a bem da verdade, de extrema valia e grande destaque no cenário intelectual brasileiro.

\section{REFERÊNCIAS BIBLIOGRÁFICAS}

Arantes, P. Um departamento francês de ultramar. SP: Paz e Terra, 1994.

Arruda, M. A. Metrópole e cultura: São Paulo no meio século XX. Bauru/SP: Edusc, 2001. pp. 201-204.

Arruda, Maria Arminda do Nascimento. Metrópole e cultura: o novo modernismo paulista em meados do século. Tempo Social, v. 2, n. 9, pp. 39-52, out. 1997.

Bourdieu, P. O poder simbólico. 5. ed. Rio de Janeiro: Bertrand Brasil, 2002.

. Homo Academicus. Paris: Les Editions de Minuit, 1984.

- As regras da arte: gênese e estrutura do campo literário. São Paulo: Companhia das Letras, 1996.

Os usos sociais da ciência. Traduçáo Denice Catani. São Paulo: Ed. Unesp, 2004.

Costa, J. C. Contribuição à história das idéias no Brasil. Rio de Janeiro: José Olympio, 1956. p. 138.

Costa, J. C. A filosofia de Augusto Comte e as origens do positivismo. São Paulo: Ed. Companhia Nacional, 1959.

. Sobre o trabalho teórico. (Entrevista.) Revista Transformação, São Paulo, Faculdade de Filosofia e Letras de Assis, v. 2, pp. 87-8, 1974.

Oliveira, Lúcia Lippi. A Sociologia do guerreiro. Rio de Janeiro: UFRJ, 1995.

Ortiz, Renato. Alienação e cultura: o Iseb. In: Ortiz, R. Cultura brasileira e identidade nacional. 4. ed. Sáo Paulo: Brasiliense, 1985. pp. 45-67.

Prado Jr., B. O problema da filosofia no Brasil. Alguns ensaios. São Paulo: Ciência da Abelha, 1985.

Toledo, C. N. Iseb: fábrica de ideologias. Sáo Paulo: Ática, 1977. 


\section{BIBLIOGRAFIA}

Bourdieu, P. Contribuição à história das ideias no Brasil. Rio de Janeiro: José Olympio, 1956.

Nobre, M. et al. (Org.). Conversas com filósofos brasileiros. São Paulo: Ed.34, 2000. 